Peer review: This article has been subject to a double blind peer review process

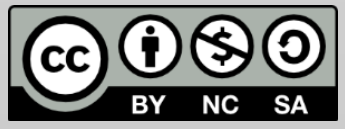

(C) Copyright: The Authors. This article is issued under the terms of the Creative Commons Attribution NonCommercial Share Alike License, which permits use and redistribution of the work provided that the original author and source are credited, the work is not used for commercial purposes and that any derivative works are made available under the same license terms.

\section{Ideals and Practices of Rationality - An Interview with Lorraine Daston}

\author{
Michael Trevor Bycroft * \\ Department of History, University of Warwick \\ *Correspondence: M.Bycroft@warwick.ac.uk
}

\begin{abstract}
Lorraine Daston is a historian of science based at the Max Planck Institute for the History of Science in Berlin, where she has directed a research group since 1995. Her career spans five decades and has included award-winning monographs such as Classical Probability in the Enlightenment (1988), Wonders and the Order of Nature (with Katherine Park, 1998), and Objectivity (with Peter Galison, 2007), as well as a large number of collective works. She visited the University of Warwick in March 2017 to deliver the Vice-Chancellor's Distinguished Lecture. In a wide-ranging interview, she spoke about the evolution of the discipline of the history of science; the research programme known as historical epistemology; the nuts and bolts of collaboration in the humanities; her current research on archives in the sciences and the humanities; and the transience of scientific theories.
\end{abstract}

Keywords: Lorraine Daston, history of science, collaboration, archives, historical epistemology, scientific progress

What is objectivity? We all know it is important, we all strive for it, and we can all identify instances of it-but what is it? One way to answer this question-and to answer the same question about other cornerstones of rationality, such as facts, laws, rules, observation, curiosity and probability-is to look the term up in a dictionary. We might also ask someone who specialises in the analysis of concepts, such as an analytic philosopher.

The problem with both approaches is that they give different results depending on when we ask the question. Dictionary definitions change from epoch to epoch, as do the opinions of philosophers, as does the pool of examples that supports their definitions.

'Of course they change,' comes the reply, 'they are getting better and better!' This may be so, but it is not the end of the story. The evolution of concepts such as 'fact' and 'law' is not as smooth as we might expect 
from their present-day appearance of solidity. These concepts have run through so many nuances, and undergone so many convulsions, that the question of which version is better fades into the background and is replaced-at least in the mind of the historian-by a range of other questions.

For example: when and why did these concepts first emerge? What accounts for their fickleness, their tendency to change suddenly after a few decades of stability? How are these conceptual changes related to changes in the everyday activities - checking pulses, labelling specimens, annotating texts - of the people who embody them? What do these changes tell us about the emotions of scientists, about scientific progress, and about the relationship between the sciences and the humanities?

These questions are at the heart of a research programme in the history of science that has produced a steady stream of ground-breaking works since its emergence in the 1970s. The clunky but convenient name for this research programme is 'historical epistemology.'

Lorraine Daston is a leading practitioner of historical epistemology. She is also a major figure in the history of science, one whose contributions to the field were recognised by the History of Science Society in 2012, when she received the Sarton Medal for lifetime scholarly achievement. She is based at the Max Planck Institute for the History of Science in Berlin, one of approximately 80 research institutes in Germany run by the Max Planck Society. The Department that she directs at the Institute lends its name to the title of this interview: 'Ideals and Practices of Rationality.' She has published on topics as diverse as monsters in seventeenthcentury England, smallpox inoculation in eighteenth-century France, Latin inscriptions in nineteenth-century Germany, and game theory in twentieth-century America.

The occasion for this conversation was Daston's visit to the Warwick campus as a speaker in the Vice-Chancellor's Distinguished Lecture Series. The conversation took place on Monday, 6 March 2017, between Daston and Michael Bycroft, in the presence of two Professors in the History Department at the University of Warwick, Maxine Berg and Giorgio Riello. The transcript has been tweaked for brevity and clarity, and explanatory notes inserted in square brackets. But the conversational tone remains, complete with digressions and exclamations, the better to convey Daston's wit and fluency.

The interview explores science and its history by way of Daston's intellectual biography. The first section covers her training in history and science in the 1970s, a tumultuous time for both disciplines. Daston then speaks in turn about her past contributions to historical epistemology; 
her extensive hands-on experience in collaborative research at the Max Planck Institute; and her current project on the use of archives in science and the humanities. The interview concludes with Daston's reflections on a question that nags at many, though perhaps not all, researchers: will my work stand the test of time?

\section{Training: history of science as a discipline}

$M B$ (Michael Bycroft): I understand that you began your undergraduate studies with the intention of becoming a scientist, before veering into history. Was there a eureka moment when you decided that history of science was the discipline for you?

LD (Lorraine Daston): Alas there was no voice calling, no genuine vocation in that sense! But it is true that I went to university with the intention to be an astronomer. I realise in retrospect this was somewhat of a childish fantasy: I come from a Greek family and I was actually christened Urania, after the muse of astronomy, and for some comical reason (nomen est omen) I felt predestined for the stars! And I simply had the good fortune as a freshman at Harvard [in 1970] to take the introductory course in the history of astronomy, which was taught by the astronomer and historian of science Owen Gingerich.

Owen was, first of all, a superlative teacher. I think many, many Harvard undergraduates, if they remember nothing else from the courses they took, will remember Owen's spectacular demonstration of Newton's three laws, including roaring into the lecture room on a little cart to demonstrate that action and reaction are equal. But he also laced his astrophysics lectures with generous doses of the history of science: noone will ever forget the stories he told about [the seventeenth-century astronomers] Kepler and Tycho and Newton and Halley. So at least as an undergraduate it seemed that the history of science was a going concern. There was no undergraduate concentration on the History of Science, but there was the concentration History and Science: you did science, and you did something in history, and that was the perfect refuge for people like me who couldn't make up their minds about what they wanted to do.

I continued in this meandering fashion and spent a year at Cambridge, doing what I thought would be preparatory work for a PhD. I had a fellowship at that point to do so in the philosophy of science, until it became abundantly clear to me that the philosophy of science I had in mind was the philosophy of science of Leibniz [German philosopher, 1646-1716], something like the Monadology, which had since migrated into science fiction and bore no resemblance whatsoever to what Anglo- 
American philosophers of science meant by that discipline. And I also realised that I was, by temperament and also I think by evidentiary predilection, an empiricist, a real grass roots empiricist. So I returned to history, and to the history of science.

This sort of trajectory is very typical of the history of science. Because there are so few programmes of the history of science, almost no-one comes to their university studies saying 'I want to be a historian of science.' We all come from some other discipline. In my generation, and perhaps also in the current generation, historians of science take an exante trajectory through the sciences, sometimes through philosophy, sometimes through history, sometimes through sociology. I think that's been extraordinarily enriching for the field. We've always had very permeable boundaries to other disciplines.

MB: In hindsight, the 1970s seem to have been a turbulent period in the historiography of science, with many new and radical ideas coming on board-major works by the American philosopher Thomas Kuhn, and the French philosopher Michel Foucault, had been published in the 1960s, and these fed into the new sociology of science that took shape early in the 1970s. How did you experience these developments at the time? Was there a feeling that change was in the air?

LD: Oh, absolutely! And I think one must also insert those disciplinary novelties into the context of political upheaval in the late 1960s and 1970s when I was a freshman in college: this would have been in 1970. The university was almost closed for protest because of the bombing of Cambodia. This ferment that you describe was part and parcel of a much larger sense of upheaval, and very much in the minds of those people who were, for example, advocating a more sociological approach to the history of science linked with broader programmes for political and social reform. It was the time amongst general historians of the rise of social history-again very much yoked to a conviction, a political conviction, that it was important to do the history of the working class, not only for scholarly reasons, but for political reasons as well. And I think very much the same spirit emanated a great deal from the debates in the history of science at the time.

It is very true that Thomas Kuhn in many ways opened the floodgatesoften in ways that later horrified Kuhn himself. For example, he never intended to create the conditions for the possibility of the Strong Programme in Edinburgh [a radical branch of the sociology of science based at Edinburgh University]. But I think it is undeniable that one single book [Kuhn's The Structure of Scientific Revolutions, 1962] absolutely galvanised the field. 
We must remember the conditions that created programmes in the history of science after World War Two. James Bryant Conant, who had been one of the chief administrators of the Manhattan Project [the USsponsored project to produce an atomic bomb during WWII], previously president of Harvard and subsequently president of Harvard, returned from that experience thinking that at least an elite of the citizenry (he believed the Harvard student population to be the future elite), even if they weren't going to become scientists, needed to learn about science in order to preserve democracy from becoming a technocracy. The history of science was going to be the vehicle for this.

So the history of science that had been created under Conant's aegis at Harvard, and which Kuhn was trained in, was history of science in the service of educating non-scientists in what science meant. Hence the Harvard Case Studies in Experimental Science [1948]. Conant's rosy view was that Harvard students - these future presidents of the United States, these future captains of industry-were not going to understand atomic physics, but they could jolly well understand Robert Boyle's experiments [on air pressure in the 1660s, a subject of one of the Harvard Case Studies]. And because science is all much of a muchness, that will suffice.

Kuhn's bomb, thrust into the midst of that group, was to say 'no, science changes absolutely irreversibly, incommensurably, from paradigm to paradigm.' This was not just an explosion for the discipline of the history of science: it was an explosion for Conant's entire programme for what the discipline was supposed to do in the post-atomic bomb world.

\section{Major past works: probability theory and the history of the self-evident}

MB: Your PhD research at Harvard led eventually to your first book, Classical Probability in the Enlightenment (1988). How did you move from astronomy to probability theory [a branch of mathematics that deals with random phenomena]?

LD: Well, already as an undergraduate I had shifted from astronomy to math, and at Cambridge I had done a thesis on projective geometry [a branch of mathematics with roots in perspective art], and had intended to pursue the history of projective geometry into my dissertation. Then I had a stroke of good fortune: at the time the library at Harvard, the Widener Library (hallowed be its name!) had a new book table where, you know, the latest publications were put on display. I was going off to babysit that night and needed a book of just the right heft: I chose it entirely by how long it was, and I had in my hand lan Hacking's The 
Emergence of Probability [1975], which, because the baby slept that night, I read from cover to cover, just as Descartes says you're supposed to read the Meditations.

And there was no going back - I was absolutely hooked! Not only on probability theory, but on the way Hacking did history, which was try to imagine the conceptual preconditions for what for us is self-evident. That's what I think 'historical epistemology' is, and although I wouldn't have been able to articulate it as a graduate student, it was a way for me to pursue my philosophical interests while thoroughly historicising them. This was a Lucretian swerve [an apt metaphor for a historian of probability theory: here Daston refers to the thesis, endorsed by the ancient Roman philosopher Lucretius, that there is an irreducible element of chance in the motion of atoms]. I never picked up projective geometry again; it was all probability theory.

MB: The title of the monograph-Classical Probability in the Enlightenment-suggests that a distinctive approach to probability prevailed in the Enlightenment. What was that approach?

LD: Yes, the title of the dissertation was perhaps more revealing in that respect: it was called The Reasonable Calculus. This was the first attempt to formalise human reason. As Hacking pointed out in his book, the mathematics, at least of early probability theory, is trivial. Certainly the mathematics becomes more sophisticated-between the correspondence between Blaise Pascal and Pierre Fermat in 1654, and the axiomatisation of probability theory by Andrey Kolmogorov in the 1930s-but it doesn't become conceptually different. So the real question is timing: why was this invented then? And what were its sources and applications?

If there's one big idea in the book, it is this: if you want to know about the sources of probability theory, you should look at its applications. Its first applications were, most obviously, to games of chance [such as gambling on the throw of a dice], but those were trivial. More ambitiously, it was applied-by the likes of Leibniz and Condorcet, Laplace and Poisson - to the law, to judgement, to testimony, to the probability of miracles, and finally to the prediction of risk, as in the case of aleatory contracts [i.e. contracts dealing with chance events], such as the purchase of wheat futures, and to life insurance. The thesis of the book is that these applications in turn inspired an enormously ambitious project, from Leibniz on through Laplace and Poisson, to take the formalism of probability and use it to create an engine of rationality, so we would no longer be dependent on our intuition of what is rational, but that we could, as Leibniz says, calculate-and that this in turn would settle disputes automatically. 
MB: You used the phrase 'historical epistemology' a moment ago, a phrase that has sometimes been applied to your own work. Would you apply that label to yourself?

LD: I should say, to begin with, that lan [Hacking], although he has been very kind, considers the word 'historical epistemology' to be an abomination-and though I was certainly inspired by him, he believes it sounds like it's been badly translated from the German! I agree with him that it is highly inelegant. It should also be said that there is a French tradition, stemming from [Gaston] Bachelard and others, sometimes called épistémologie historique, which is not unaffiliated with this. The word itself is an iridescent word: it shimmers in different colours depending on who is looking at it. So I would simply add the caveat that the word itself is probably not the best guide to the sort of work that's being done.

What I consider myself to be doing is the history of the self-evident, ie. histories of categories which seem to us so necessary to the way we think now that's inconceivable to imagine being without them. Yet they nonetheless have a history. Concepts like probability, which creates, for the first time since ancient logic, between the extremes of true or false, a spectrum of degrees of evidence: more true, less true, and the like. Other examples are the book with Peter Galison on objectivity [Objectivity, 2007], the edited volume on observation [Histories of Scientific Observation, 2011] - a category that seems so crashingly banal and yet has a history-and the book on rules [in preparation].

Maxine Berg: Yes, could I just ask a question in there? It's really interesting how probability theory got all these applications in everyday economic life, and yet it doesn't seem to have been picked up, in the eighteenth century anyway, by the early practitioners of political economy. That doesn't come until the early nineteenth century. Why the delay?

LD: I think there are at least two answers to that very interesting question. One of them is very simple: where are you going to get the numbers? Nobody is keeping reliable statistics, the only halfway reliable statistics-and I emphasise halfway, italicised-are life expectancy statistics that have been collected in some polities since the sixteenth century for completely different reasons. Both Protestant and Catholic polities require parishes to register births and deaths, which at least provides some raw material. This data is by no means solid in terms of consistency or comprehensiveness, but at least you have a foothold. This leads people like De Moivre and others in the eighteenth century to believe that you could at least in principle have, not so much mathematically based life insurance, but mathematically based 
annuities - because annuities are much more important to governments in that epoch, which are selling them to earn money. This falls absolutely flat for other reasons we can go into, but otherwise, there are no statistics and that means it is very difficult to use probability theory, to get numbers to affix to your probabilities.

But the other reason-which I think is deeper, and you see glimmers of it in [William] Whewell [1794-1866], who of course is an intimate friend of John Herschel [1792-1871], author of the Preliminary Discourse to Natural Philosophy [1831] -is that their ambitions are grander. They do not want simple probabilistic models, they want deductive models, and in so far as these models are empirical they should be of true causes, on the model of Newtonian axiomatised celestial and terrestrial mechanics. So probability just seems infra dig [beneath their dignity]. I really don't think it's until [William Stanley] Jevons [1835-1882] that the economists begin to exploit the possibilities of probabilistic models. Of course there's something that can retrospectively be called expected utility in Daniel Bernouilli's [1700-1782] work on probabilistic expectation, with regards to the [smallpox] inoculation problem in the mid-eighteenth century and the St. Petersburg paradox [a gambling paradox named after the Russian Academy in which it was first published, in 1738]. But that's not picked up on, to my knowledge at least, by the economists. It's seen as a tool of economic and political decision-making, but not as a way of modelling the economy.

Historian Joyce Appleby has argued that in the late seventeenth century the market emerges as having stable enough regularities that it can be an object of enquiry. I wonder the extent to which other objects that we now consider self-evidently economic behaviour-taking risks on the stock market and the like-were seen as being stable enough to admit of that kind of modelling. Certainly life insurance brokers at first balked at using mathematics; they just didn't think it was a stable enough phenomenon. Things could change from moment to moment and you didn't want to be corseted by the premiums that had been calculated by your actuaries if you heard that in South Carolina an epidemic of malaria had broken out thereby sending, you know, your claims spiralling.

\section{Working methods: collaboration in the humanities}

MB: Your CV is impressive for the sheer quantity of collaborative work you have done in the last thirty years, including no less than thirteen edited collections...

$M \times B:$... and two co-authored monographs! 
LD: Yes, I think we should divide the two genres, because I think they are somewhat different genres, or so it seems to me empirically.

There are the books written with a few other authors, like the book Wonders and the Order of Nature [1998] with Katharine Park, and the book Objectivity [2007] with Peter [Galison] - those grew out of conversations, and conversations that straddled the conventional periodisation within the history of science. Katy is a medievalist, Peter is a modernist, and I' $m$ in the middle. We were all in graduate school together, and these were the sorts of conversations that graduate students have-although they don't know it, time hangs heavy on their hands. And we were all desperately trying to avoid writing our dissertations! So, one had the leisure for that kind of conversation. And it became clear to all of us that these are topics you couldn't do justice to individually, at least given the periodisation in which we'd been trained, and that some kind of more longue durée history was going to be necessary simply to note the changes-you know, to get a sense of the inflection points.

We didn't realise at the time-at least Katy and I certainly didn't realise at the time-that it would be professional suicide to dedicate a lot of time to this project, because then as now junior scholars are evaluated individually. So we always did it left-handedly, as it were.

But the second reason it survived that long, very long, gestation period, is because it was so rewarding. It was so much fun, we learned so much, and obviously there was a division of labour: Katy's the medievalist, I'm the early modernist, but each of us would select texts that she thought were key texts, and we would read and discuss those together, so we could stabilise our analytical categories. And then there is the somewhat pugnacious pleasure of testing the argument out, and then the other person mounting the strongest possible counter argument to it, to make sure it will stand the test-a kind of discipline that in principle we could all create, but our lives are too hectic to arrange that kind of intensity of engagement, especially if each of us immersed in his or her own individual project.

The other, the larger projects [the edited collections], I had a model for. Directly after I finished my PhD, I had the enormous good fortune to be recruited for a project that lan Hacking and Nancy Cartwright, two philosophers with very strong historical interests then at Stanford, and the German philosopher, Lorenz Kruger, who also had very strong historical interests, were organising in the Centre for Interdisciplinary Research at Bielefeld in Germany. I was a very junior member of a group of-I guess there must have been about twenty to twenty-five of us in all-that was supposed to work on The Probabilistic Revolution [1987]. It 
was lan and Nancy and Lorenz's project. It didn't start out as a collaborative project in the sense it became, but because of the enormous force of those three personalities it became one.

There was a moment that was absolutely formative for me. Someone suggested: 'we should have someone taken minutes of our discussions'. And the three youngest members of the group-me, Mary Morgan and Ted Porter-looked at each other, absolutely certain one of us would be the dogsbody assigned this task. As we were steeling ourselves for the inevitable, lan piped up, the most senior member in the room, and said, 'Oh, I'll do it! And then we'll take turns.' The establishment, through that simple act, of an absolutely egalitarian intellectual community, is seared in memory as a model of what that can be like. And it's the precondition for those kinds of collaborative projects.

So that became the model for the collaborative projects at the Max Planck Institute. The challenge at the Institute was: we have these resources-what can we do that a university can't do? We have to create a framework in which people can pursue their individual research, otherwise their goose is cooked-especially if they're young. But also, a framework which will contribute to projects that none of us can do alone, that can reach across many, many centuries and if we're lucky continents. And having groups than meet not once, not twice but three or four times to draft, redraft, discuss, criticise, redraft again until we come up with a volume--which may look like an ordinary edited volume but I can tell you is the condensed labour of five years and many, many drafts to get to that point.

MB: In these collaborations, do you ever follow the standard historians' conference procedure, i.e. getting all the authors in a room and having them each present their paper in turn, with questions from the audience at the end of each paper?

LD: In most cases, no, and I'll explain the exception in a moment. In most cases, the group is chosen, and we all send in drafts ahead of time, and a reader [i.e. a single document containing all the drafts] is prepared. Each paper is assigned at least two commentators, one near to the field, so you have an expert vetting it, and one far from the field, so that somebody can say: would this make any sense whatsoever to a classicist, for example, if it's a paper on nineteenth-century statistics? And then the discussions begin. So for the most part there's very little stand-anddeliver $Q$ and $A$. We plunge in medias res, everyone is expected to have done his or her homework, and because of the commentaries-each of us doing two or three commentaries on different papers-we have confronted at least some of the text as a referee and as a discussant. 
The exceptions to this format were some of the smaller working groups, like the one on Cold War rationality [How Reason Almost Lost its Mind, 2013], where we had a workshop first. This was in part because we weren't sure whether there was a topic there. So we (Princeton historian Michael Gordin and myself) invited people who we knew were working broadly on the history of science in the Cold War, and we presented papers in the normal fashion. But the group that met subsequently for the entire summer the year thereafter came with our prepared papers and the usual carousel began turning.

MB: An obvious question to ask, from one editor to another: how do you get people to submit their draft papers on time?

LD: I think that a lot of it has to do with the fact that we know we're going to be sitting around a seminar table face-to-face. Something quite primordial about being embodied human beings kicks in at that point. Once everyone goes back home it's very hard of course, and all the usual problems of being an editor then crop up. One imagines oneself, alas, as a gigantic mosquito buzzing in the authors' ears...

But for the most part the loyalties cemented by these groups linger. I certainly feel this about The Probabilistic Revolution [1987]. These people became my family, a kind of ersatz family-in one case literally, I married one of the other members of the group! It changed my life! But I think it creates lines of connection, not among all the members of the group, but among many of the members of the group, generating a kind of intellectual and social solidarity, which helps to stiffen discipline to get papers in on time.

$M B$ : These edited collections emerge from a particular institution, the Max Planck Institute for the History of Science in Berlin. You mentioned that this Institute is designed to do what a university cannot. How much of your method of collaboration can be transferred to universities?

LD: There are three directors at the Max Planck Institute for the History of Science, at present Jürgen Renn, Dagmar Schäfer and myself. Each director really has a different vision of how to organise a department. So what I have described about the way my department works should not be generalised even to this one Institute-there are multiple ways of working.

In my department, we've always operated with an umbra/penumbra model. That is, for a given topic, for example the history of scientific observation, there is a core group that is working towards a collective publication. And then there is a penumbra of people, especially people at the postdoc stage, who are working on their own projects, which are relevant to the main topic, but as single-authored publications because 
that is what is needed for the advancement of their scholarly careers. There is a great deal of informal toing-and-froing between the umbra and penumbra.

Much of what happens in the penumbra is immediately recognisable from a university perspective: individual scholars working on interesting individual projects. The only difference is that, as at an Institute for Advanced Study, they have the time and the freedom to work (mostly!) free of distractions. So that part could perhaps - though I wonder under modern circumstance to what degree-be transplanted to the university. But the umbra, the Working Groups producing collective publications, really does depend on the resources of something like our Institute. It's partly the stamina to be able to keep a project going. For most funding schemes supporting academic research, there's usually a relentless rhythm of results expected. The Max Planck Society is a great good exception in that regard. It was designed to be a counterweight to that kind of pressure. So these conditions are exceptional.

\section{Current project: the sciences of the archives}

$M B:$ The most recent of these working group projects is connected to the talk you will give this evening, which is entitled The Sciences of the Archives: Big Sciences, Big Humanities and the Pathos of Positivism. How did this project come about?

LD: It was a direct successor of the project on observation. One of the many lessons from that project was that observation, even when it was not a learned practice, when it was a practice pursued by sailors on their ships and shepherds on their fields, was a transgenerational collective project. Observation is futile without some way of preserving the observations. For example, NASA's Five Millennium Canon of Lunar Eclipses includes observations made by the ancient Chaldeans [tenth to sixth centuries BC]. Certain sciences depend on archives that reach far back into the past.

The other thing that emerged from the project on observation was how very recent and often very distorting the perspective of current classifications of knowledge is, especially the current divide between the sciences and the humanities. If you look at the practices of keeping archives, whether it's the archaeologists or the meteorologists, they're very, very similar - often because they're the same people who have learnt from one another. These are the scribal practices of note-taking, filing, collating, retrieving. They've been updated with every new media revolution-such as print, and now digital media-but they are the same procedures. 
One of the first digital humanities projects was by a Jesuit (not surprisingly - the Jesuits are always in the van!) named Roberto Busa. This Busa had written his doctoral dissertation on the preposition 'in' in [the writings of the thirteenth-century theologian] Saint Thomas Aquinas. He'd done this by the old-fashioned method of humanist collation. But when in the 1940s IBM cards [perforated pieces of card, an early form of computer programme] started to come along, he thought 'this could be done automatically!' So began one of the very first digital humanities projects, on the works of Aquinas. The practices of making concordances by hand and by machine were absolutely continuous in Busa's mind: these are the same procedures, he reasoned, we just have to transfer them to the new medium. And although nobody really knows what the algorithm of Google Search is, we know enough about it to know it's the old scholarly practice of looking at citations, collecting citations, page rankings, et cetera.

So, these practices are both enormously long-lived and absolutely pervasive-not across all disciplines, but certainly across many. That is the origin of the project: imagine we define the sciences of the archive entirely by those practices rather than by subject matter, whether it was human or natural, what would we come up with?

MB: Your talk is about these long-range practices, but also about the distinctiveness of the nineteenth century. What was special about that period?

LD: Two things happen. First, the classical philologists [scholars of ancient languages], then the scientists, realise that nothing is forever in their disciplines, that the price of progress is that their work will be obsolete before they retire. And the second thing that happens is these disciplines become objects of enormous cultural prestige for nations competing on the world stage in the nineteenth century....

MxB: ...like the porcelain collections!

LD: Exactly! So that nations-especially European nations like France and Britain, and later more peripheral ones such as the United States-are willing to invest enormous sums in the projects of these disciplines. We know, perhaps most spectacularly, of the excavations of the French government at Delphi and the German government at Olympia. But there were also, of course, Egyptian explorations, by the French then the Germans, and astronomical transit expeditions, and eclipse expeditions, and so on. Never, except perhaps in ancient Babylonia, have governments invested so heavily in such projects in the hopes of proving their cultural superiority. 
I don't think it's an accident-though I'm not in a position to prove this at the moment-that they do this at a time when they must justify their imperialistic adventures in regard to other cultures. In the case of the French, some scholars justified the conquest of Northern Africa with the claim that the Arabs had gotten stuck in the thirteenth century. Until then, they had been the leading astronomers and had somehow-so the story went-lapsed into a period of stagnation. Colonisation was necessary to catapult them into the era of modern science.

\section{A glimpse into the future}

MB: The aim of your project on archives is, crudely put, to show that science is less changeable than we thought-to show that some scientific projects have lasted centuries, even millennia. Yet the aim of your earlier work on historical epistemology was to show that science is more changeable than we thought - to show that concepts such as observation and objectivity have varied greatly across the centuries. Do you see a tension between these two aims?

LD: I think it is actually a corollary of the turn towards practices. Of course, I believe there is novelty in the realm of practices, but I also believe that unlike theories, which have the lifetime of mayflies, practices endure. They are very seldom, once they're attained, discarded. The real challenge is to-Nancy Cartwright has been doing quite brilliant work on this recently-is how you braid together practices, each of which has its distinct history, distinct origins, and original uses.

Nancy has been thinking about the relatively new practice of randomised clinical trials versus the age-old practice of clinical observation in medicine. The latter is still absolutely essential: the San Francisco doctor who discovered AIDS did so by the tried and true method that a Hippocratic doctor might have employed-correlating symptoms, and noticing regularities in ways of life and regimen, et cetera, et cetera, creating a conjecture that could then be experimentally tested. Randomised clinical trials - which increasingly have come to dominate, especially the medical sphere but also the social science sphere-are the invention of Ronald Fisher at the agricultural station at Rothamsted [then Rothamsted Experimental Station, now Rothamsted Research, in Hertfordshire] at the beginning of the twentieth century. So these have entirely different histories. They're both very important practices in many sciences now, especially in the biomedical sciences. How do you weave them together? Not put them in a head-on collision with each other, but weave them together to make a stronger rope of evidence. 
Historians have been doing this as well. All of us-well! at least Maxine who is in my generation, and probably Giorgio [Riello's] generation as well-were taught to cross-examine our sources, to read them with a gimlet eye, to read them against the grain, to put them in relationships of interrogation one to the other-this is the achievement of [Jean] Mabillon, [Leopold von] Ranke, and other historians since the seventeenth century. But there are new practices. For example, the really interesting work which is now being done on literary texts, which is to examine the use of characteristic stylistic traits - not the use of metaphor, but something like how many commas Shakespeare uses-in order to establish authorship, and the like. That's a new procedure, another arrow in our quiver. Or for those who work on, let us say, nomadic tribes in central Asia in the Middle Ages, where there are very few texts, we can use archaeological evidence and now perhaps paleogenetic evidence. So every discipline is always expanding its armamentarium of methods. We just have to figure out how to consolidate them.

MB: How should we feel about the fact that, even though our practices persist, our theories don't? Is this a reason for alarm or scepticism?

LD: Oh, no! I am not like poor Alexander von Humboldt [German scientist, 1769-1859] who did find it alarming that the books on his shelves were no longer being read! No-as late as Max Weber [German sociologist, 1864-1920], it was a melancholy thought that all we have worked on will be outdated a generation hence. For me, in contrast, the most important thing to do is to open up a new area of enquiry. So I fully expect that other scholars will work on observation, will work on probability theory, will work on Cold War rationality, and they will no doubt contradict our theses, they will enlarge them, they will rethink them, but that as an object of enquiry these themes will persist. That's the goal: not to have the last word but the first.

And also, if possible - this is what lan Hacking's book [The Emergence of Probability, 1975] did for me-to think of a new way of asking questions. lan's book is a good example. The criticisms from specialists that have rained down on lan's head-earlier anticipations of this or that aspect of probability theory, for example-is to me of secondary importance.

What is important is that lan asked a new kind of question, and what is important is that we are still asking his questions, regardless of whether we are giving different answers. So no, I'm not sad! Indeed I'd be saddest if that did not happen! My vanity perhaps would be flattered if nobody ever wrote a rebuttal to anything I wrote. But my rational self would say: this means that what l've written is not very interesting. If nobody feels 
inspired enough to take exception to it, then it might as well have been written on water.

\section{Acknowledgements}

This interview owes a great deal to the stamina of the interviewee, the initiative of Maxine Berg, the technical support of Yuexi Liu, and the editorial assistance of Joshua Patel.

\section{References}

Conant, J. B. (1948), Harvard Case Studies in Experimental Science, Cambridge, MA: Harvard University Press

Daston, L., Classical Probability in the Enlightenment (1988), Princeton: Princeton University Press

Daston, L. (ed.) (2017), Science in the Archives: Pasts, Presents, Futures, Chicago: Chicago University Press

Daston, L., P. Erickson, J. L. Klein, R. Lemov, T. Sturm, and M. D. Gordin (eds.) (2013), How Reason Almost Lost Its Mind: The Strange Career of Cold War Rationality, Chicago: Chicago University Press

Daston, L. and P. Galison (2007), Objectivity, New York: Zone Books

Daston, L., L. Krüger and M. Heidelberger (eds.) (1987), The Probabilistic Revolution; Vol. I: Ideas in History, Cambridge, MA: MIT Press

Daston, L. and E. Lunbeck (eds.), Histories of Scientific Observation, Chicago: University of Chicago Press, 2011

Daston, L. and K. Park (1998), Wonders and the Order of Nature, New York: Zone Books

Hacking, I. (1975), The Emergence of Probability, Cambridge: Cambridge University Press

Kuhn, T. (1962), The Structure of Scientific Revolutions, Chicago: University of Chicago Press

To cite this article:

Bycroft, M. (2017). Ideals and Practices of Rationality - An Interview with Lorraine Daston. Exchanges: The Warwick Research Journal, 4(2), 173-188. Retrieved from:

http://exchanges.warwick.ac.uk/index.php/exchanges/article/view/154 